\title{
Crystallization and Properties of Poly(ethylene terephthalate) Copolymers Containing 5-tert-Butyl Isophthalic Units
}

Darwin P.R. Kint ${ }^{1}$, Elisabet Rudé ${ }^{2}$, Joan Llorens $^{2}$, Sebastián Muñoz-Guerra ${ }^{1^{*}}$

1Departament d'Enginyeria Química, Universitat Politècnica de Catalunya, Escola Tècnica Superior d'Enginyers Industrials de Barcelona, Diagonal 647, Barcelona 08028, Spain

${ }^{2}$ Departament d'Enginyeria Química i Metal·lurgica, Universitat de Barcelona, Facultat de Química, Martí i Franquès 1, Barcelona 08028, Spain 


\section{Abstract}

The influence of incorporating 5-tert-butyl isophthalic units ( ${ }^{\mathrm{t}} \mathrm{BI}$ ) in the polymer chain of poly(ethylene terephthalate) (PET) on the crystallization behaviour, crystal structure, and tensile and gas transport properties of this polyester was evaluated. Random poly(ethylene terephthalate-co-5-tert-butyl isophthalate) copolyesters $\left(\mathrm{PET}^{\mathrm{t}} \mathrm{BI}\right)$ containing between 5 and $40 \mathrm{~mol} \%$ of ${ }^{\mathrm{t}} \mathrm{BI}$ units were examined. Isothermal crystallization studies were performed on amorphous glassy films at $120{ }^{\circ} \mathrm{C}$ and on molten samples at $200{ }^{\circ} \mathrm{C}$ by means of differential scanning calorimetry. Furthermore, the non-isothermal crystallization behaviour of the copolyesters was investigated. It was observed that both crystallinity and crystallization rate of these PET copolymers tend to decrease largely with the comonomeric content, except for the copolymer containing $5 \mathrm{~mol} \%$ of ${ }^{\mathrm{t}} \mathrm{BI}$ units, which crystallized faster than PET. Fibre X-ray diffraction patterns of the semicrystalline $\mathrm{PET}^{\mathrm{t}} \mathrm{BI}$ copolyesters proved that they adopt the same triclinic crystal structure as PET with the comonomeric units being excluded from the crystalline phase. Although $\mathrm{PET}^{\mathrm{t}} \mathrm{BI}$ copolyesters became brittle for higher contents in ${ }^{\mathrm{t}} \mathrm{BI}$, the tensile modulus and strength of PET were barely affected by copolymerization. The incorporation of ${ }^{t} \mathrm{BI}$ units slightly increased the permeability of PET, but copolymers containing up to 20 mol $\%$ of the comonomeric units were still able to present barrier properties.

Keywords: Poly(ethylene terephthalate); PET; copolyester; 5-tert-butyl isophthalate; crystallization; structure; mechanical properties; gas permeability. 


\section{Introduction}

The modification of the chemical structure of poly(ethylene terephthalate) (PET) to attain new products with improved specific properties is a matter of great industrial interest. Copolymerization using minor amounts of a second glycol or diacid comonomer is an approach frequently used to diminish the crystallinity and crystallization rate and to modify the thermal properties of PET. The purpose is introducing into the polymer a certain amount of chain defects capable of hindering the molecular mobility and crystal packing without altering significantly the general genuine behaviour of the parent homopolymer. Due to its good commercial accessibility, the utilization of isophthalic acid as the second acidic comonomer has been extensively investigated to repress the tendency of PET towards crystallization [1-6]. However, PET copolymers containing isophthalic acid display a glass-transition temperature $\left(T_{g}\right)$ lower than that of PET, which constitutes a serious shortcoming of these copolyesters. The utilization of isophthalic acid with bulky side groups enhancing chain stiffness is considered a valuable alternative. Thus, the enhancing effect of the presence of 5-tert-butyl isophthalic units $\left({ }^{\mathrm{t}} \mathrm{BI}\right)$ on the $T_{g}$ of a wide variety of polycondensates including polyamides, polyesters, and polyurethanes has been reported $[7,8]$. More recently, several polyarylates and polyaramides containing ${ }^{\mathrm{t}} \mathrm{BI}$ units were described to be amorphous and to display largely improved solubility $[9,10]$. Furthermore, a series of PET related copolyesters prepared from polymethylene glycol, terephthalic acid, and 5-tert-butyl isophthalic acid were claimed to present a reduced tendency to crystallize and to have $T_{g} s$ higher than that of PET [11,12]. It was concluded that the effect exerted by the 5-tert-butyl side group on the crystallization and thermal properties is the same in all cases and that such effect arises from the changes in intermolecular and intramolecular interactions caused by the bulkiness of this group.

Recently we have reported on the synthesis and characterization of poly(ethylene terephthalate-co-5-tert-butyl isophthalate) copolyesters, abbreviated $\mathrm{PET}^{\mathrm{t}} \mathrm{BI}$ [13]. A series of copolymers covering a wide range of compositions and with a random microstructure was obtained by bulk 
polycondensation. This systematic study showed that $P E T^{t} \mathrm{BI}$ copolymers are thermally stable polymers with a melting temperature $\left(T_{m}\right)$ lower than that of $\mathrm{PET}$ and with a $T_{g}$ increasing parallel to the content of ${ }^{\mathrm{t}} \mathrm{BI}$ units.

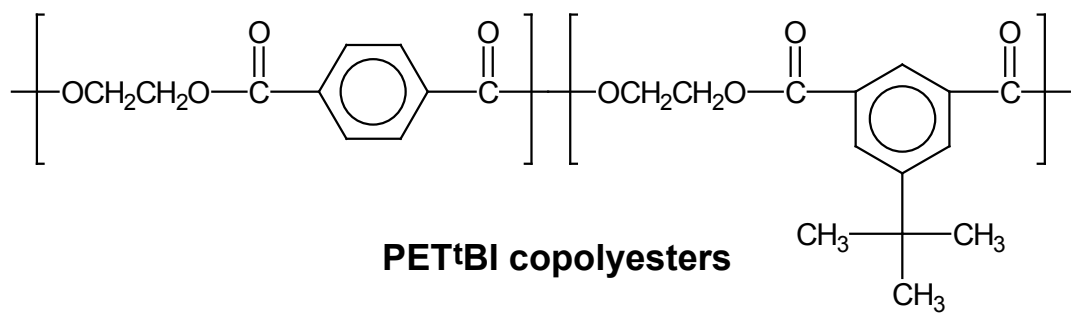

The distinguishing feature of $\mathrm{PET}^{\mathrm{t}} \mathrm{BI}$ copolymers is that they are able to combine a lower crystallizability with a higher $T_{g}$, an exceptional combination of high convenience for the potential application of PET in the manufacture of amorphous thick sheets for high temperature applications. In this paper we want to report in detail on the crystallization behaviour of $P E T^{t} B I$ from both the glassy state and from the melt. Furthermore, the crystal structure of these copolyesters is definitely determined from fibre wide-angle diffraction data. Since the changes produced in the mechanical and barrier properties of PET by copolymerization will be determinant for the potential development of these copolymers, the tensile and gas transport properties have been also evaluated for different comonomer compositions.

\section{Experimental}

\subsection{Materials}

$\mathrm{PET}^{\mathrm{t}} \mathrm{BI}$ copolymers containing $5,10,15,20,30$, and $40 \mathrm{~mol} \%$ of 5 -tertbutyl isophthalic units were prepared by bulk polycondensation of ethylene glycol and mixtures of dimethyl terephthalate and 5-tert-butyl isophthalic acid using tetrabutyl titanate as a catalyst. It was ascertained by ${ }^{13} \mathrm{C}$ and ${ }^{1} \mathrm{H}$ NMR analysis that all copolyesters have a completely random microstructure and that they contain less than $\sim 4.2 \mathrm{~mol} \%$ of diethylene glycol units. A detailed account of the synthesis and chemical characterization of these compounds is given 
elsewhere [13]. Catalana de Polímers, S.L. (El Prat De Llobregat, Barcelona, Spain) kindly provided the PET homopolymer used in this work. The characteristics of all these polyesters that are relevant to the present work are comparatively listed in Table 1.

Table 1. Characterization data of PET and $P E T^{t} B I$ copolyesters. ${ }^{a}$

\begin{tabular}{|c|c|c|c|c|c|c|c|c|c|}
\hline \multirow[b]{2}{*}{ Polyester } & \multicolumn{2}{|c|}{ Composition } & \multirow[b]{2}{*}{ DEG } & \multicolumn{2}{|c|}{ Molecular Weights } & \multirow[b]{2}{*}{ Density } & \multicolumn{3}{|c|}{ Thermal Properties } \\
\hline & $X_{\mathrm{T}}$ & $X_{\mathrm{tBI}}$ & & $M_{\mathrm{n}}$ & $M_{\mathrm{w}}$ & & $T_{g}$ & $T_{m}$ & $\Delta H_{m}$ \\
\hline PET & 100 & 0 & 2.2 & 18,300 & 51,200 & 1.340 & 78 & 258 & 45.2 \\
\hline $\mathrm{PET}_{95}{ }^{\mathrm{t}} \mathrm{BI}_{5}$ & 94.8 & 5.2 & 1.6 & 17,300 & 37,900 & 1.321 & 82 & 240 & 36.7 \\
\hline $\mathrm{PET}_{90}{ }^{\mathrm{t}} \mathrm{Bl}_{10}$ & 90.1 & 9.9 & 1.2 & 21,300 & 56,200 & 1.316 & 81 & 230 & 26.6 \\
\hline $\mathrm{PET}_{85}{ }^{\mathrm{t}} \mathrm{Bl}_{15}$ & 85.8 & 14.2 & 1.1 & 16,500 & 41,300 & 1.302 & 81 & 215 & 18.2 \\
\hline $\mathrm{PET}_{80}{ }^{\mathrm{t}} \mathrm{BI}_{20}$ & 81.6 & 18.4 & 2.2 & 19,100 & 37,000 & 1.280 & 85 & 200 & 8.0 \\
\hline $\mathrm{PET}_{70}{ }^{\mathrm{t}} \mathrm{Bl}_{30}$ & 70.3 & 29.7 & 4.2 & 18,900 & 43,000 & 1.273 & 86 & 167 & 0.7 \\
\hline $\mathrm{PET}_{60}{ }^{t} \mathrm{BI}_{40}$ & 61.7 & 38.3 & 2.3 & 29,400 & 65,600 & 1.252 & 87 & - & - \\
\hline
\end{tabular}

${ }^{a}$ Data taken from reference [13]. Polymer composition give in mol \%; DEG, diethylene glycol content in mol \%; Density taken from amorphous samples in $\mathrm{g} \mathrm{mL}^{-1} ; T_{g}$, glass-transition temperature in ${ }^{\circ} \mathrm{C} ; T_{m}$, melting temperature of pristine samples in ${ }^{\circ} \mathrm{C} ; \Delta H_{m}$, melting enthalpy in $\mathrm{J} \mathrm{g}^{-1}$.

\subsection{Measurements}

Powder and fibre wide-angle X-ray diffraction patterns were obtained on flat photographic films in a modified Statton camera using monochromatic CuK $\alpha$ radiation (wavelength $=1.5418 \AA$ ) and they were calibrated with molybdenum sulfide. Oriented samples were obtained by mechanical stretching under heating at the appropriate temperatures. Differential scanning calorimetry (DSC) experiments were performed on a Perkin-Elmer Pyris 1 instrument calibrated with indium. Thermograms were obtained from 3-6 mg samples at heating and cooling rates of $10{ }^{\circ} \mathrm{C} \mathrm{min}-1$ under a nitrogen flow of $20 \mathrm{~mL} \mathrm{~min}^{-1}$. Isothermal crystallization studies were performed both on amorphous films at $120{ }^{\circ} \mathrm{C}$ and on molten samples at $200{ }^{\circ} \mathrm{C}$. Glassy, unoriented, amorphous films with a thickness of about $20 \mu \mathrm{m}$ were obtained by melt compression followed by immersion into ice-cold water. X-ray diffraction diagrams from these films showed no signs of crystallinity. Annealing treatments were performed for 2 hours at 10 or $20{ }^{\circ} \mathrm{C}$ below the melting temperature of the isothermally crystallized samples. Non-isothermal crystallization behavior of molten samples 
was examined at cooling rates of $2,5,10,20$, and $40^{\circ} \mathrm{C} \mathrm{min}^{-1}$. Densities of the amorphous, isothermally crystallized, and annealed films were measured by the flotation method at $20^{\circ} \mathrm{C}$ using heptane/tetrachloromethane mixtures.

Tensile testing was performed on rectangular specimens $(55 \mathrm{~mm} \times 5$ $\mathrm{mm}$ ) cut from amorphous, isotropic films having a thickness of about $200 \mu \mathrm{m}$. The tensile tests were conducted at room temperature on a Zwick BZ2.5/TN1S universal tensile testing apparatus operating at a constant cross-head speed of $10 \mathrm{~mm} \mathrm{~min}^{-1}$ using a $0.5 \mathrm{~N}$ pre-load and a grip-to-grip separation of $20 \mathrm{~mm}$. All reported tensile data represent an average of at least six independent measurements.

Gas transport properties of PET and $\mathrm{PET}_{90}{ }^{\mathrm{t}} \mathrm{Bl}_{10}$ and $\mathrm{PET}_{80}{ }^{\mathrm{t}} \mathrm{Bl}_{20}$ copolyesters were evaluated using amorphous films with a thickness between 40 and $80 \mu \mathrm{m}$. Permeability to nitrogen, oxygen, and carbon dioxide gases was tested at $25^{\circ} \mathrm{C}$, at the respective pressures of $10.5,7.5$, and $5.0 \mathrm{~atm}$. To make the films, the material was sandwiched between two steel platens covered with Teflon-coated aluminum foil and the thickness was controlled by the appropriate ring spacers. The platens were placed in a press and heated at $280{ }^{\circ} \mathrm{C}(\mathrm{PET})$, $250{ }^{\circ} \mathrm{C}\left(\mathrm{PET}_{90}{ }^{\mathrm{t}} \mathrm{BI}_{10}\right)$, and $225{ }^{\circ} \mathrm{C}\left(\mathrm{PET}_{80}{ }^{\mathrm{t}} \mathrm{BI}_{20}\right)$ for $5 \mathrm{~min}$ without pressure, then the pressure was increased to 1 ton and finally released. This cycle was repeated for 2 and 3 tons with the platens being held at each pressure for $1 \mathrm{~min}$ to be finally quenched in cold water. The thickness of the film was taken as the arithmetic average of a number of measurements made with a micrometer all over the whole area of the sheet. Permeability measurements were carried out in a pressure-rise constant volume system. Initially the membrane, which was placed in a diffusion cell, was evacuated from any residual gas by applying high vacuum to both sides of the membrane for 24 hours as a minimum. Then at time $t=0$ the upstream side of the membrane was exposed to the desired gas at the desired pressure, $p_{\text {up }}$ and pressures on the downstream chamber were measured as a function of time. 


\section{Results and discussion}

\subsection{Crystallization studies}

With the purpose of evaluating the crystallizability of $P E T^{t} B I$ with regard to the copolymer composition and the influence of the 5-tert-butyl isophthalate group on the crystallinity, glassy films of PET and $\mathrm{PET}^{\mathrm{t}} \mathrm{BI}$ copolyesters containing 5,10 , and $15 \mathrm{~mol} \%$ of comonomeric units were isothermally crystallized at $120{ }^{\circ} \mathrm{C}$ for 2 hours. $\mathrm{PET}^{\mathrm{t}} \mathrm{BI}$ copolyesters richer in ${ }^{\mathrm{t}} \mathrm{BI}$ units were unable to crystallize under these conditions. The absence of crystallinity in the initial films was assessed by DSC and X-ray diffraction. The density of these amorphous films decreased with the content in ${ }^{t} \mathrm{BI}$ units due to merely compositional effects. As expected, the density was found to increase upon crystallization for all samples. Additionally, molten samples of the same polymers were isothermally crystallized at $200{ }^{\circ} \mathrm{C}$ for 2 hours. It was observed that the time at which the onset of crystallization happened increased with the content of ${ }^{\mathrm{t}} \mathrm{BI}$ units in the polyester. $\mathrm{PET}_{85}{ }^{\mathrm{t}} \mathrm{Bl}_{15}$ was found to be unable to crystallize isothermally at $200{ }^{\circ} \mathrm{C}$. The evolution of the relative crystallinity, $X_{t}$, versus crystallization time for both modes of crystallization is shown in Fig. 1a. It can be observed that $X_{t}$ increased in a sigmoid manner in both cases and for all polyesers, and that the crystallization rate decreased significantly for PET ${ }^{\mathrm{t}} \mathrm{BI}$ copolymers containing 10 and $15 \mathrm{~mol} \%$ of ${ }^{\mathrm{t}} \mathrm{BI}$ units. It is remarkable that $\mathrm{PET}_{95}{ }^{\mathrm{t}} \mathrm{BI}_{5}$ crystallized faster than PET upon crystallization from the glassy state at $120^{\circ} \mathrm{C}$. The Avrami crystallization parameters, $k$ (crystallization growth rate) and $n$, were attained by plotting the following double-logarithmic equation:

$$
\log \left[-\ln \left(1-X_{t}\right)\right]=\log k+n \log \left(t-t_{0}\right)
$$

where $t$ and $t_{0}$ are the elapsed time and the onset time for crystallization, respectively. The Avrami plots of $\log \left[-\ln \left(1-X_{t}\right)\right]$ versus $\log \left(t-t_{0}\right)$ for PET and the $\mathrm{PET}^{\mathrm{t}} \mathrm{BI}$ copolymers isothermally crystallized at 120 and $200{ }^{\circ} \mathrm{C}$ are shown in Fig. 1b. In the former case, the plots show a linear tendency for all polyesters corresponding to the so-called primary crystallization stage, which includes 

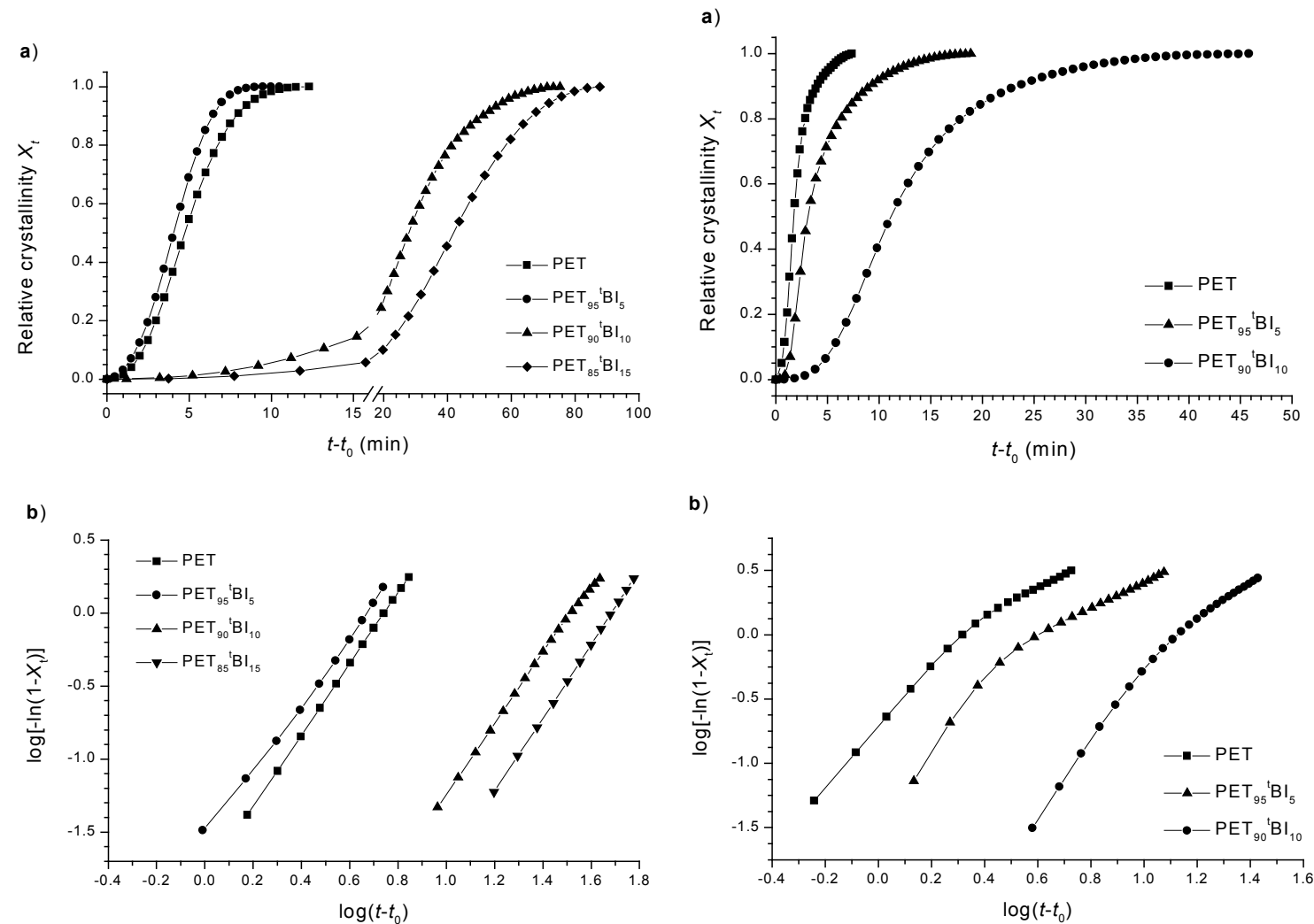

b)

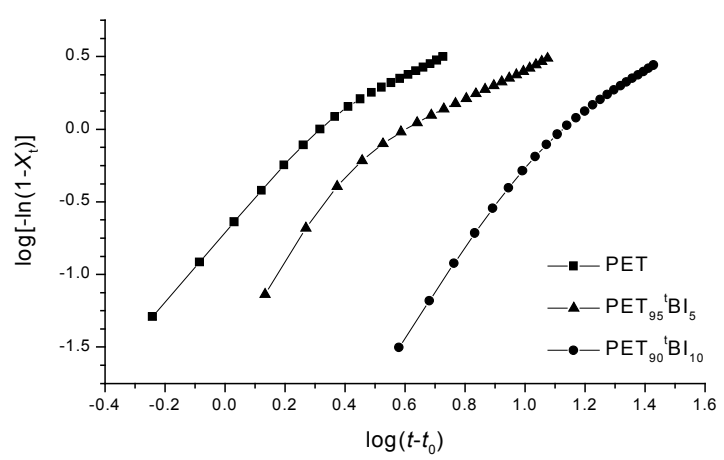

Fig. 1. (a) Relative crystallinity $X_{t}$ versus crystallization time and (b) Avrami plots for PET and PET ${ }^{t} B I$ copolymers. Left: Isothermally crystallized from the glassy state at $120{ }^{\circ} \mathrm{C}$ for $2 \mathrm{~h}$. Right: Isothermally crystallized from the melt at $200{ }^{\circ} \mathrm{C}$ for $2 \mathrm{~h}$.

nucleation and crystal growth. Conversely, the plots resulting from crystallization from the melt display clearly a two-regime behaviour, the slope for the first regime being significantly greater than that for second regime. According to what is reported for PET copolymers containing isophthalic units [3], the two regimes correspond to primary and secondary crystallization, respectively. The Avrami parameters estimated from the slope and the interception of the crystallization plots are summarized in Table 2. The Avrami exponents were found to range from 2.2 to 2.9 for the first crystallization regime suggesting that all the polyesters crystallized by a three-dimensional spherulitic growth with predominant heterogeneous nucleation, likely promoted by the remaining catalyst. The crystallization decelerating effect exerted by the presence of 10 or $15 \mathrm{~mol} \%$ of 5-tert-butyl isophthalic units is brought into evidence by the increase of the onset time of crystallization and the decrease of the growth rate for these copolyesters when compared with PET. The overall 
effect is reflected in the increase of the crystallization half-time, $t_{1 / 2}$, with composition, which multiplied by about ten when passing from PET to $\mathrm{PET}_{85}{ }^{\mathrm{t}} \mathrm{BI}_{15}$ for isothermal crystallization at $120{ }^{\circ} \mathrm{C}$.

Table 2. Crystallization parameters and thermal properties of isothermally crystallized and annealed ${ }^{\mathrm{a}} \mathrm{PET}$ and PET ${ }^{\mathrm{t}} \mathrm{BI}$ copolyesters.

\begin{tabular}{|c|c|c|c|c|c|c|c|c|}
\hline \multirow[b]{2}{*}{ Polyester } & \multirow[b]{2}{*}{$t_{0}^{\mathrm{b}}$} & \multicolumn{3}{|c|}{ Avrami Parameters $^{c}$} & \multirow[b]{2}{*}{ Density $^{d}$} & \multicolumn{3}{|c|}{ Thermal Properties } \\
\hline & & $n$ & $\log k$ & $t_{1 / 2}$ & & $T_{m}^{\mathrm{e}}$ & $\Delta H_{m}^{\mathrm{e}}$ & $X_{c}^{f}$ \\
\hline \multicolumn{9}{|l|}{ PET } \\
\hline $120^{\circ} \mathrm{C}$ (glass) & 0.48 & 2.4 & -1.81 & 4.77 & $1.402(1.421)$ & $250(255)$ & $41.8(56.9)$ & $35(47)$ \\
\hline $200^{\circ} \mathrm{C}$ (melt) & 0.43 & 2.3 & -0.72 & 1.75 & n.d. & $249(255)$ & $40.5(50.4)$ & $34(42)$ \\
\hline \multicolumn{9}{|l|}{$\mathrm{PET}_{95}{ }^{\mathrm{t}} \mathrm{BI}_{5}$} \\
\hline $120^{\circ} \mathrm{C}$ (glass) & 0.52 & 2.2 & -1.51 & 4.07 & $1.365(1.403)$ & $239(239)$ & $35.2(51.0)$ & $29(43)$ \\
\hline $200^{\circ} \mathrm{C}$ (melt) & 0.64 & 2.3 & -1.31 & 3.18 & n.d. & $235(238)$ & $38.1(40.8)$ & $32(34)$ \\
\hline \multicolumn{9}{|l|}{$\mathrm{PET}_{90}{ }^{\mathrm{t}} \mathrm{Bl}_{10}$} \\
\hline $120^{\circ} \mathrm{C}$ (glass) & 2.80 & 2.4 & -3.62 & 27.67 & $1.337(1.372)$ & $225(227)$ & $18.5(41.7)$ & $15(35)$ \\
\hline $200^{\circ} \mathrm{C}$ (melt) & 3.20 & 2.9 & -3.17 & 11.33 & n.d. & $231(235)$ & $29.2(21.9)$ & $24(18)$ \\
\hline \multicolumn{9}{|l|}{$\mathrm{PET}_{85}{ }^{\mathrm{t}} \mathrm{Bl}_{15}$} \\
\hline $120^{\circ} \mathrm{C}$ (glass) & 17.3 & 2.5 & -4.26 & 43.80 & $1.313(1.343)$ & $215(216)$ & $15.2(31.9)$ & $13(27)$ \\
\hline $200^{\circ} \mathrm{C}$ (melt) & \multicolumn{8}{|c|}{ Unable to crystallize } \\
\hline
\end{tabular}

${ }^{a}$ Values for the annealed samples are given in parenthesis. ${ }^{b}$ Onset crystallization time (min). ${ }^{\mathrm{c}}$ Avrami exponent $n$, crystallization growth rate $k\left(\mathrm{~min}^{-1}\right)$, and crystallization half-time $t_{1 / 2}(\mathrm{~min}){ }^{\mathrm{d}}$ Density $\left(\mathrm{g} \mathrm{mL}^{-1}\right)$ determined by the flotation method. ${ }^{\mathrm{e}}$ The melting temperature $\left(T_{m} ;{ }^{\circ} \mathrm{C}\right)$ and enthalpy $\left(\Delta H_{m} ; \mathrm{J} \mathrm{g}^{-1}\right)$ of the isothermally crystallized samples were registered by DSC at a heating rate of $10^{\circ} \mathrm{C} \mathrm{min}{ }^{-} .{ }^{f}$ The degree of crystallinity was estimated from the melting enthalpy against the melting enthalpy of fully crystalline PET $\left(\Delta H_{\mathrm{m}}=119.8 \mathrm{~J} \mathrm{~g}^{-}\right)$. n.d. not determined.

The DSC traces obtained from the crystallized samples are shown in Fig. 2. DSC heating traces of the samples crystallized from the glassy state at 120 ${ }^{\circ} \mathrm{C}$ display two melting peaks, a very weak one at an approximate constant temperature of $136{ }^{\circ} \mathrm{C}$, and a second strong one above $200{ }^{\circ} \mathrm{C}$, whose exact position clearly depends on the copolyester composition. The DSC heating scans from the samples crystallized from the melt at $200{ }^{\circ} \mathrm{C}$ contain only a multiple high temperature endotherm above $200{ }^{\circ} \mathrm{C}$, which in this case consists of two or three peaks. The presence of multiple peak endotherms is commonly observed in the DSC heating traces of crystallized PET, and it is generally associated to the existence of populations of crystallites differing in size or in 
crystal perfection. The origin of such complex behaviour remains unclear and its explanation is still object of controversy.

a)

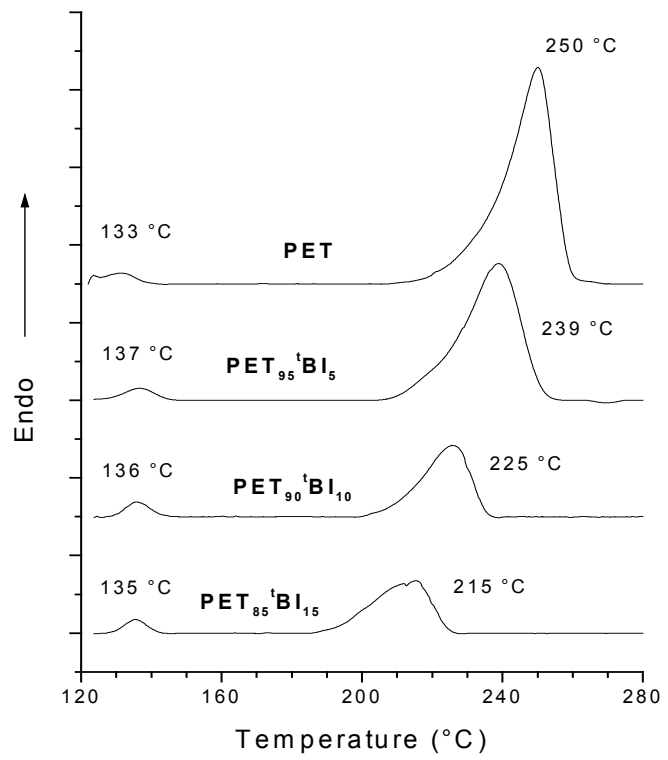

a)

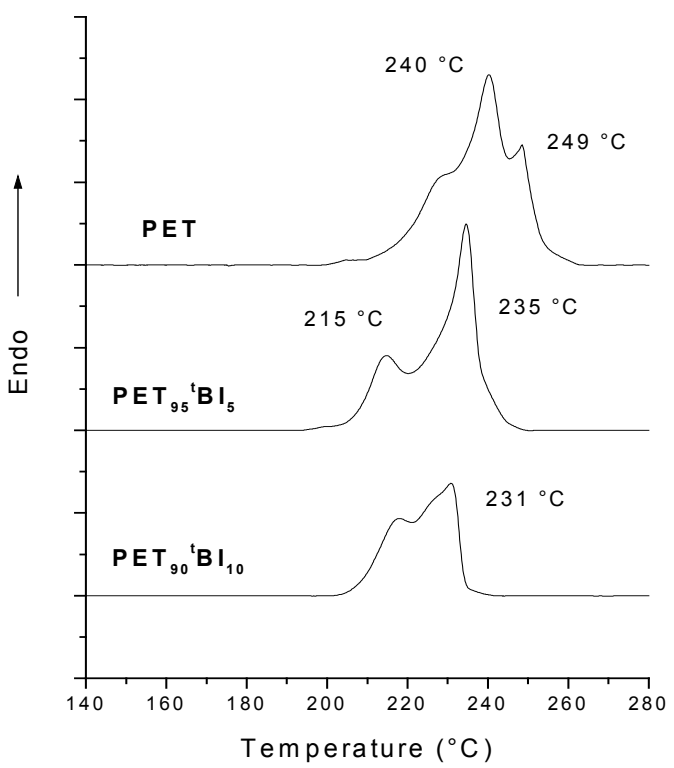

b)

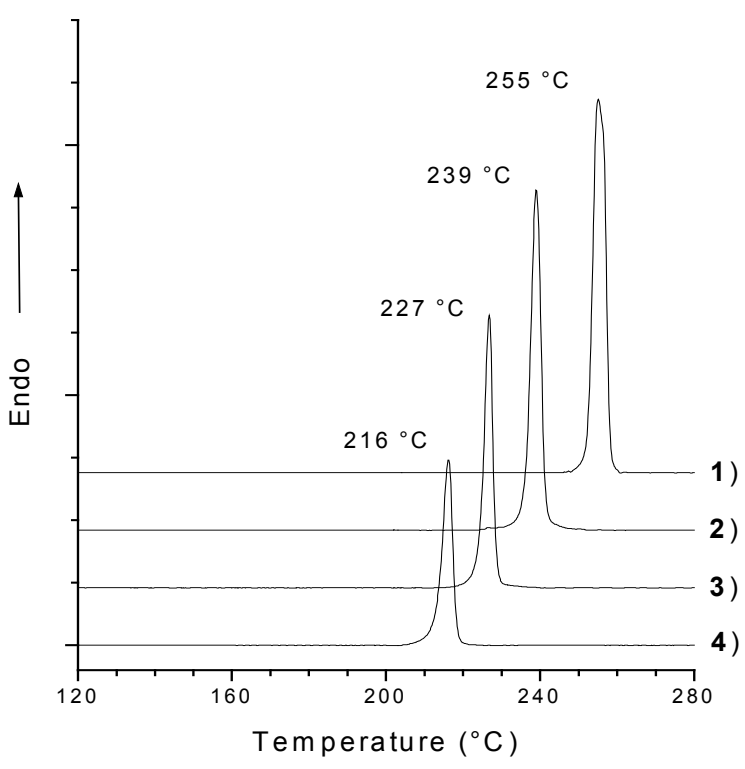

b)

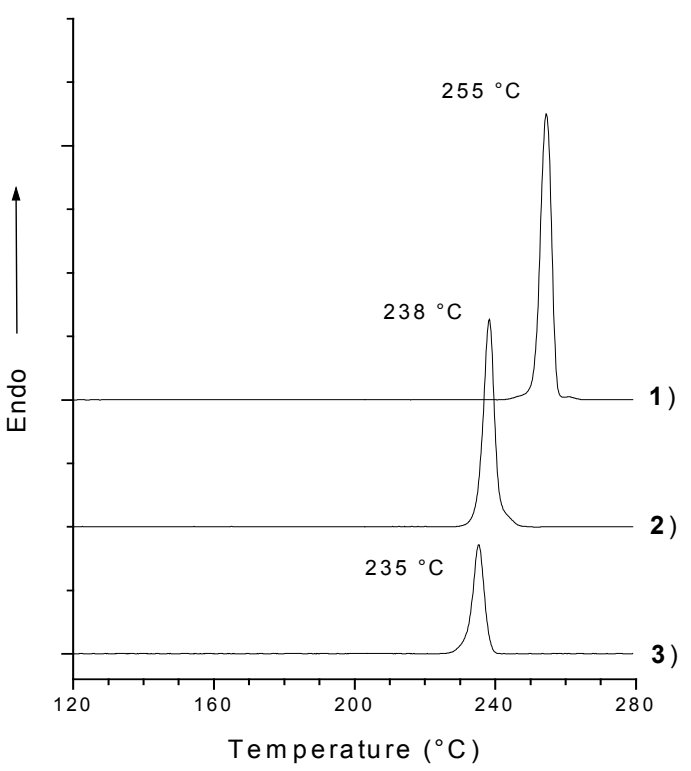

Fig 2. DSC heating traces of (a) isothermally crystallized and (b) subsequent annealed PET and PET ${ }^{\mathrm{t} B I}$ copolyesters. Top: Isothermally crystallized from the glassy state at $120{ }^{\circ} \mathrm{C}$. Bottom: Isothermally crystallized from the melt at $200{ }^{\circ} \mathrm{C}$. (1) PET, (2) $\mathrm{PET}_{95}{ }^{\mathrm{t}} \mathrm{BI}_{5}$, (3) $\mathrm{PET}_{90}{ }^{\mathrm{t}} \mathrm{Bl}_{10}$, (4) $\mathrm{PET}_{85}{ }^{\mathrm{t}} \mathrm{Bl}_{15}$.

Both melting temperature and crystallinity of the isothermally crystallized samples were increased by subjecting them to annealing treatments at $10{ }^{\circ} \mathrm{C}$ (samples crystallized from the melt) or $20{ }^{\circ} \mathrm{C}$ (samples crystallized from the 
glassy state) below their respective melting temperatures for a period of 2 hours. The heating scans of the annealed samples are also shown in Fig. 2 and the results attained upon such treatment are included in Table 2. The DSC heating traces of the annealed samples showed sharper melting peaks displaced towards higher temperatures. An increase in density concomitant to the increase in crystallinity was observed after annealing. A comparative inspection of the relative changes occurring in the melting enthalpy upon annealing revealed that the treatment is more efficient when applied to isothermally crystallized glassy samples of $\mathrm{PET}^{\mathrm{t}} \mathrm{BI}$ copolyesters enriched in ${ }^{\mathrm{t}} \mathrm{BI}$ units. The general trend observed for the melting temperature and enthalpy versus copolyester composition was maintained in the annealed samples, revealing that the depressing effect of the ${ }^{t} \mathrm{BI}$ units on the crystallinity of PET is exerted even after the crystal perfectioning treatment.

Furthermore, non-isothermal crystallization experiments were conducted for comparison. Upon cooling from the melt at 2, 5, 10, 20, and $40{ }^{\circ} \mathrm{C} \mathrm{min}^{-1}$, PET and $\mathrm{PET}^{\mathrm{t}} \mathrm{BI}$ copolyesters containing 5 and $10 \mathrm{~mol} \%$ of ${ }^{\mathrm{t}} \mathrm{BI}$ units were able to crystallize, whereas $\mathrm{PET}_{85}{ }^{\mathrm{t}} \mathrm{Bl}_{15}$ remained amorphous. As can be seen in Fig. $3 a$, the melting and crystallization temperatures were found to decrease with the content of ${ }^{\mathrm{t}} \mathrm{BI}$ units at all cooling rates.

a)

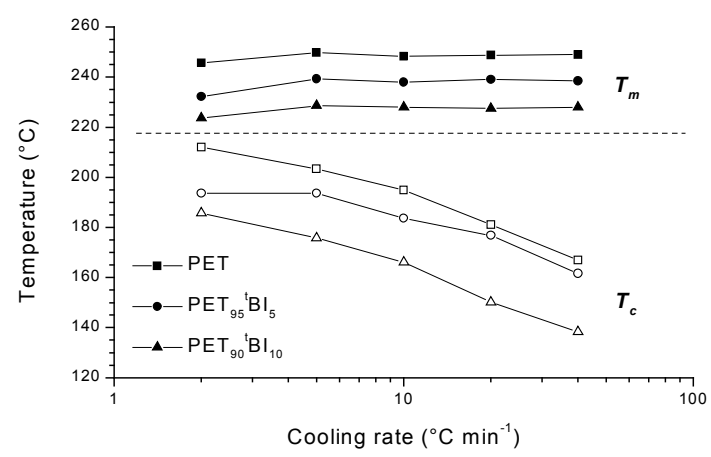

b)

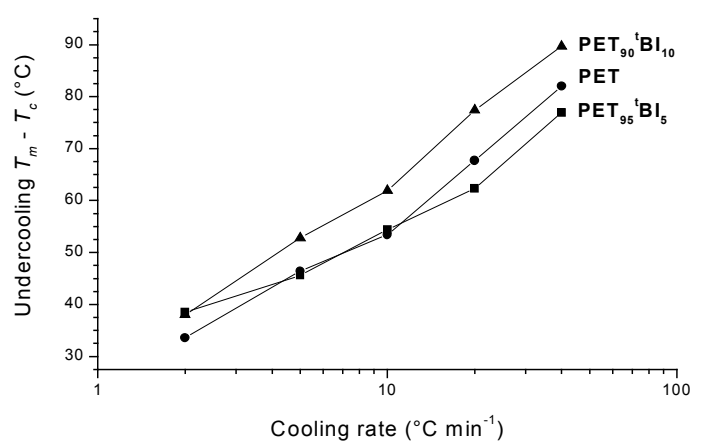

Fig. 3. (a) $T_{m}$ and $T_{c}$ versus the cooling rate for $P E T, P E T_{95}{ }^{t} B I_{5}$, and $P E T_{90}{ }^{t} \mathrm{BI}_{10}$. (b) The degree of undercooling versus the cooling rate for PET and $\mathrm{PET}^{\mathrm{t}} \mathrm{BI}$ samples containing 5 and $10 \mathrm{~mol} \%$ of comonomeric units. 
Furthermore, it was observed for all polymers that the crystallization temperature decreased with increasing cooling rate, whereas the melting temperature of the crystallized samples slightly increased instead. Heating traces of PET and $\mathrm{PET}{ }_{90}^{\mathrm{t}} \mathrm{BI}_{10}$ samples crystallized at 20 and $40{ }^{\circ} \mathrm{C} \mathrm{min}^{-1}$ showed additional cold-crystallization upon heating, whereas this phenomenon was not observed for $\mathrm{PET}_{95}{ }^{\mathrm{t}} \mathrm{BI}_{5}$. The degree of undercooling $\left(T_{\mathrm{m}}-T_{\mathrm{c}}\right)$ for the nonisothermal crystallized $\mathrm{PET}$ and both $\mathrm{PET} \mathrm{T}^{\mathrm{t}} \mathrm{BI}$ copolymers was compared and the resulting data are illustrated in Fig. 3b. It can be seen that the degree of undercooling is the smallest for $\mathrm{PET}_{95}{ }^{\mathrm{t}} \mathrm{BI}_{5}$. This, together with the aforementioned absence of cold-crystallization, is taken indicative that $\mathrm{PET}_{95}{ }^{\mathrm{t}} \mathrm{BI}_{5}$ crystallizes faster than PET under non-isothermal conditions as well.

\subsection{Crystal structure of $P E T^{t} B I$ copolyesters}

As shown in the previous sections, the incorporation of the 5-tert-butyl isophthalic units in the chain of PET entails a significant decrease in the crystallinity of this polyester, so that copolymers containing more than $20 \mathrm{~mol} \%$ of ${ }^{\mathrm{t}} \mathrm{BI}$ units appear to be unable to crystallize. These results can be readily explained by assuming that the isomorphic replacement of the terephthalic by 5 tert-butyl isophthalic units in the crystal lattice of these copolyesters is highly improbable due to the disturbing effect that the bulky tert-butyl side group would presumably introduce therein.

To ascertain the crystal structure of $\mathrm{PET}^{\mathrm{t}} \mathrm{BI}$, films and fibres of copolyesters with 5,10 , and $15 \mathrm{~mol} \%$ of ${ }^{\mathrm{t}} \mathrm{BI}$ units were examined by wide-angle $X$-ray diffraction. Illustrative pictures resulting from this analysis are depicted in Fig. 4 for the case of $\mathrm{PET}_{90}{ }^{\mathrm{t}} \mathrm{BI}_{10}$. Films isothermally crystallized at $120{ }^{\circ} \mathrm{C}$ for 2 hours yielded poorly defined Debye-Sherrer patterns with similar spacings and intensities for both PET and PET ${ }^{\mathrm{t}} \mathrm{BI}$. They all consist of three diffuse rings arising mainly from $h k 0$ planes, indicative of a deficiently crystallized structure. Upon annealing, much sharper diffraction patterns characteristic of a wellcrystallized structure were obtained for PET and $\mathrm{PET}^{\mathrm{t}} \mathrm{BI}$ copolyesters for 
whichever composition. These results are in full agreement with the abovepresented DSC data revealing that the three copolyesters were crystalline and how annealing treatments augmented crystallinity.
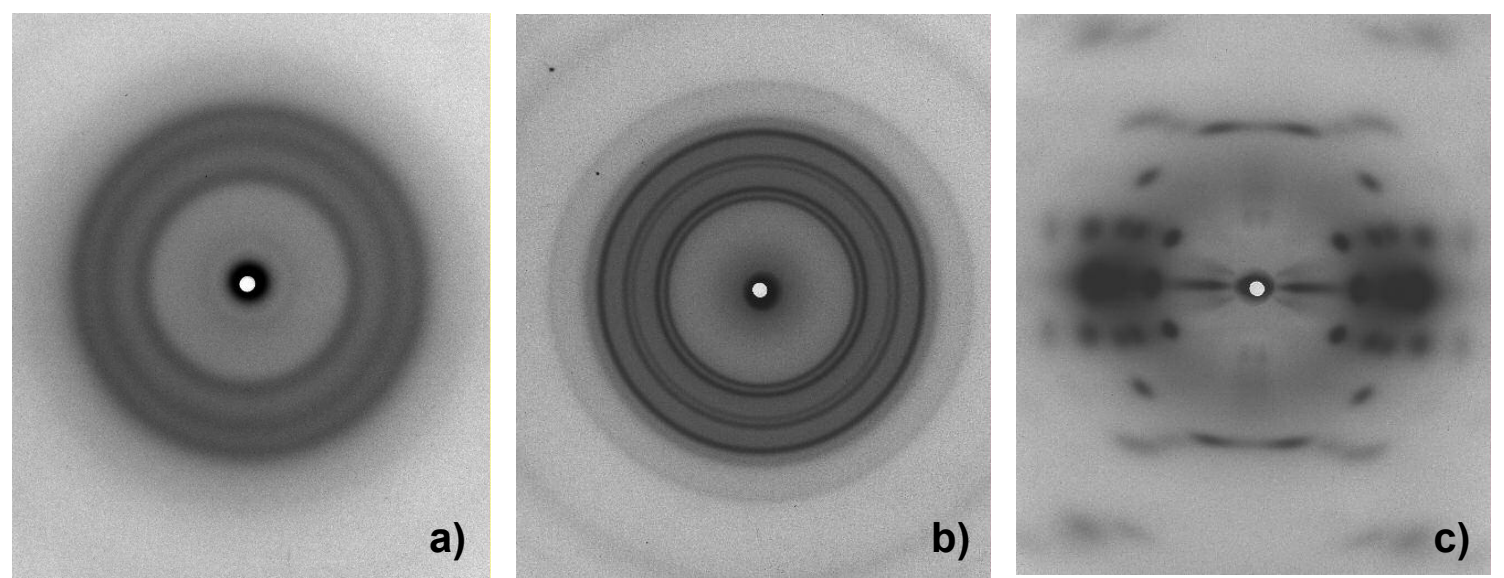

Figure 4. WAXD patterns of $\mathrm{PET}_{90}{ }^{\mathrm{t}} \mathrm{Bl}_{10}$ : (a) isothermally crystallized film, (b) annealed film, and (c) fiber sample. The fiber axis is vertical.

Fibre X-ray diffraction patterns of well-oriented fibres for the $P E T^{t} \mathrm{BI}$ copolyesters were obtained and compared with that for PET. All crystalline $P E T^{t} B I$ produced fibre diffraction patterns with similar spacings and intensities to the fibre diffraction pattern of PET. Indexing of such patterns could be therefore made on the basis of the triclinic crystal lattice of PET with parameters $a_{0}=4.56 \AA, b_{0}=5.94 \AA, c_{0}=10.75 \AA, \alpha=98.5^{\circ}, \beta=118^{\circ}$, and $\gamma=112^{\circ}$. All $d-$ spacings observed for PET and $P E T^{\mathrm{t}} \mathrm{BI}$ are summarized in Table 3. The extremely good coincidence of these spacings with those of PET, both in powder and fibre patterns, leads to the conclusion that the crystallized $P E T^{t} B I$ copolyesters adopt the same triclinic crystalline structure as PET and that the ${ }^{t} \mathrm{~B}$ I should be excluded from the crystalline lattice. Note that deviations in the $d-$ spacing values of $P E T^{t} B I$ with respect to $P E T$ are less than $2 \%$. 
Table 3. Observed and calculated X-ray spacings of PET and PET ${ }^{t} B I$ copolyesters.

\begin{tabular}{|c|c|c|c|c|c|c|c|c|c|c|c|c|}
\hline & \multirow[b]{3}{*}{$h$} & \multirow[b]{3}{*}{$k$} & \multirow[b]{3}{*}{ I } & \multirow[b]{3}{*}{$d_{h k l}^{a}(\AA)$} & \multicolumn{8}{|c|}{$d_{\text {observed }}(\AA)$} \\
\hline & & & & & \multicolumn{4}{|c|}{ Powder X-ray Diffraction } & \multicolumn{4}{|c|}{ Fibre X-ray Diffraction } \\
\hline & & & & & PET & $95 / 5$ & $90 / 10$ & $85 / 15$ & PET & $95 / 5$ & $90 / 10$ & $85 / 15$ \\
\hline \multirow[t]{3}{*}{$\|=0$} & 0 & 1 & 0 & 5.06 & 5.07 & 5.04 & 5.02 & 5.08 & 5.08 & 5.06 & 5.08 & 5.07 \\
\hline & 1 & -1 & 0 & 3.94 & 3.97 & 3.91 & 3.89 & 3.92 & 3.93 & 3.94 & 3.92 & 3.94 \\
\hline & 1 & 0 & 0 & 3.47 & 3.40 & 3.43 & 3.48 & 3.48 & 3.45 & 3.46 & 3.47 & 3.48 \\
\hline \multirow[t]{7}{*}{$\|=1$} & 0 & -1 & 1 & 5.40 & 5.48 & 5.42 & 5.46 & 5.44 & 5.41 & 5.39 & 5.42 & 5.38 \\
\hline & $\begin{array}{l}-1 \\
-1\end{array}$ & $\begin{array}{l}1 \\
0\end{array}$ & $\begin{array}{l}1 \\
1\end{array}$ & $\begin{array}{l}4.17 \\
4.13\end{array}$ & 4.11 & 4.13 & 4.16 & 4.13 & 4.11 & 4.12 & 4.17 & 4.13 \\
\hline & 0 & 1 & 1 & 3.78 & & & & & 3.75 & 3.71 & 3.72 & 3.76 \\
\hline & 1 & -1 & 1 & 3.20 & 3.17 & 3.19 & 3.21 & 3.17 & 3.20 & 3.21 & 3.20 & 3.19 \\
\hline & 0 & -2 & 1 & 2.74 & & & & & & & & \\
\hline & $\begin{array}{c}1 \\
-1\end{array}$ & $\begin{array}{l}0 \\
2\end{array}$ & $\begin{array}{l}1 \\
1\end{array}$ & $\begin{array}{l}2.73 \\
2.72\end{array}$ & 2.77 & 2.72 & 2.75 & 2.71 & 2.70 & 2.72 & 2.71 & 2.72 \\
\hline & -1 & -1 & 1 & 2.70 & & & & & & & & \\
\hline$\|=2$ & -1 & 1 & 2 & 3.60 & & & & & 3.60 & 3.58 & 3.59 & 3.60 \\
\hline \multirow[t]{2}{*}{$\|=3$} & -1 & 0 & 3 & 3.37 & & & & & 3.38 & 3.40 & 3.39 & 3.40 \\
\hline & -1 & 1 & 3 & 2.85 & & & & & 2.88 & 2.84 & 2.83 & 3.87 \\
\hline$\|=4$ & 0 & -2 & 4 & 2.12 & & & & & 2.15 & 2.14 & 2.16 & 2.15 \\
\hline
\end{tabular}

${ }^{a}$ Indexing and spacings calculated for a triclinic unit cell of parameters $a_{0}=4.56 \AA, b_{0}=5.94 \AA, c_{0}=0.75$ $\AA, \alpha=98.5^{\circ}, \beta=118^{\circ}$, and $\gamma=112^{\circ}$.

\subsection{Tensile and gas transport properties}

Tensile data, such as the Young's modulus $(E)$, the maximum tensile strength $\left(\sigma_{\max }\right)$, and the elongation at break $\left(\varepsilon_{\text {break }}\right)$ were determined for amorphous, non-oriented PET and $\mathrm{PET}^{\mathrm{t}} \mathrm{BI}$ copolyester samples and the results are given in Table 4. It can be concluded from these data that both the Young's modulus and the maximum tensile stress remained essentially unchanged upon copolymerization. Conversely, a considerable decrease in the elongation at break took place as the content of the copolymer in ${ }^{\mathrm{t}} \mathrm{BI}$ units increased, so that $\mathrm{PET}^{\mathrm{t}} \mathrm{BI}$ became ductile for ${ }^{\mathrm{t}} \mathrm{BI}$ contents above $30 \mathrm{~mol} \%$.

Permeability measurements of PET and $\mathrm{PET}^{\mathrm{t}} \mathrm{BI}$ copolyesters containing 10 and $20 \mathrm{~mol} \%$ of ${ }^{\mathrm{t}} \mathrm{Bl}$ units were carried out in a pressure-rise constant volume system by the conventional time-lag method. Downstream pressures were 
plotted against time, and from the extrapolation of the steady-state part of the curve, the intercept with the time axis, the time-lag, $\theta$, was obtained. The diffusion coefficient, $D$, was calculated as $D=L^{2} / 6 \theta$, $\mathrm{L}$ being the thickness of the film. The permeability constant $P$ is calculated from the slope of the steadystate part of the $p$-t plot using the following equation:

$$
P=\frac{T_{\text {STP }}}{p_{\text {STP }}} \frac{V L}{\mathrm{~A} T p_{\text {up }}} \frac{\mathrm{d} p(t)}{\mathrm{d} t}
$$

where $V$ is the volume of the system, $p$ the pressure recorded versus time $t, p_{\text {up }}$ is the applied upstream pressure, $T$ is the absolute temperature, $A$ is the effective area of the film, and $T_{\mathrm{STP}}$ and $p_{\mathrm{STP}}$ are the temperature and pressure under standard conditions. The solubility coefficient $S$ is then calculated from the diffusion and the permeability coefficients as $S=P / D$.

Diffusion, solubility, and permeability coefficients determined for the transport of $\mathrm{N}_{2}, \mathrm{O}_{2}$ and $\mathrm{CO}_{2}$ through $\mathrm{PET}, \mathrm{PET} 90{ }^{\mathrm{t}} \mathrm{Bl}_{10}$, and $\mathrm{PET}_{80}{ }^{\mathrm{t}} \mathrm{BI}_{20}$ films are compared in Table 4. As it could be expected from the disturbing packing effect caused by the presence of the tert-butyl side group, diffusion was observed to increase with the content of ${ }^{\mathrm{t}} \mathrm{BI}$ units for the three gases that were investigated. On the contrary, the solubility of the gases decreased with the incorporation of the ${ }^{\mathrm{t}} \mathrm{BI}$ units. These composition effects appeared more pronounced as the molecular size of the gas diminished. The consequence of such opposite trend for $D$ and $S$ coefficients is to attenuate the influence of composition on permeability, a result of interest for the potential use of $P E T^{t} B I$ as barrier polymers. 
Table 4. Tensile and gas transport properties of amorphous PET and PET'BI copolyesters.

\begin{tabular}{|c|c|c|c|c|}
\hline \multicolumn{5}{|l|}{ Tensile Properties $^{a}$} \\
\hline Polyester & $\begin{array}{c}{[\eta]^{b}} \\
\left(d L g^{-1}\right)\end{array}$ & $\begin{array}{c}\mathrm{E} \\
(\mathrm{MPa})\end{array}$ & $\begin{array}{c}\sigma_{\max } \\
(\mathrm{MPa})\end{array}$ & $\begin{array}{c}\text { Ebreak } \\
(\%)\end{array}$ \\
\hline PET & 0.63 & 1440 (165) & $37(5)$ & $82(28)$ \\
\hline $\mathrm{PET}_{95}{ }^{\mathrm{t}} \mathrm{BI}_{5}$ & 0.57 & $1230(140)$ & $35(6)$ & $88(16)$ \\
\hline $\mathrm{PET}_{90}{ }^{t} \mathrm{Bl}_{10}$ & 0.58 & $1290(100)$ & $38(4)$ & $60(29)$ \\
\hline $\mathrm{PET}_{85}{ }^{\mathrm{t}} \mathrm{Bl}_{15}$ & 0.52 & $1080(85)$ & $27(4)$ & $32(11)$ \\
\hline $\mathrm{PET}_{80}{ }^{\mathrm{t}} \mathrm{BI}_{20}$ & 0.48 & $1240(60)$ & $28(2)$ & $16(5)$ \\
\hline $\mathrm{PET}_{70}{ }^{\mathrm{t}} \mathrm{BI}_{30}$ & 0.55 & $1190(105)$ & $31(7)$ & $22(8)$ \\
\hline $\mathrm{PET}_{60}{ }^{\mathrm{t}} \mathrm{BI}_{40}$ & 0.57 & 1445 (120) & $41^{c}(4)$ & $3^{c}(1)$ \\
\hline
\end{tabular}

Gas Transport Properties ${ }^{d}$

\begin{tabular}{|c|c|c|c|c|}
\hline Gas & Polyester & $\begin{array}{c}P \cdot 10^{15} \\
{\left[\mathrm{~cm}^{3}(\mathrm{STP}) \cdot \mathrm{cm} \cdot \mathrm{cm}^{-2} \cdot \mathrm{s}^{-1} \cdot \mathrm{Pa}^{-1}\right]}\end{array}$ & $\begin{array}{c}D \cdot 10^{9} \\
{\left[\mathrm{~cm}^{2} \cdot \mathrm{s}^{-1}\right]}\end{array}$ & $\begin{array}{c}S \cdot 10^{6} \\
{\left[\mathrm{~cm}^{3}(\mathrm{STP}) \cdot \mathrm{cm}^{-3} \cdot \mathrm{Pa}^{-1}\right]}\end{array}$ \\
\hline \multirow[t]{3}{*}{$\mathrm{N}_{2}$} & PET & 0.68 & 1.1 & 0.61 \\
\hline & $\mathrm{PET}_{90}{ }^{\mathrm{t}} \mathrm{Bl}_{10}$ & 1.5 & 3.9 & 0.40 \\
\hline & $\mathrm{PET}_{80}{ }^{\mathrm{t}} \mathrm{BI}_{20}$ & 5.7 & 30 & 0.19 \\
\hline \multirow[t]{3}{*}{$\mathrm{O}_{2}$} & PET & 4.5 & 4.6 & 0.97 \\
\hline & $\mathrm{PET}_{90}{ }^{\mathrm{t}} \mathrm{Bl}_{10}$ & 7.4 & 8.9 & 0.82 \\
\hline & $\mathrm{PET}_{80}{ }^{\mathrm{t}} \mathrm{Bl}_{20}$ & 8.1 & 12 & 0.67 \\
\hline \multirow[t]{3}{*}{$\mathrm{CO}_{2}$} & PET & 21 & 1.5 & 13 \\
\hline & $\mathrm{PET}_{90}{ }^{\mathrm{t}} \mathrm{Bl}_{10}$ & 28 & 2.1 & 14 \\
\hline & $\mathrm{PET}_{80}{ }^{\mathrm{t}} \mathrm{Bl}_{20}$ & 32 & 2.3 & 14 \\
\hline
\end{tabular}

${ }^{a} \mathrm{E}$ is the Young's modulus, $\sigma_{\max }$ is the maximum tensile stress, and $\varepsilon_{\text {break }}$ is the elongation at break. The standard deviations are given in parenthesis. ${ }^{\mathrm{b}}$ Intrinsic viscosity measured in dichloroacetic acid at $25^{\circ} \mathrm{C}$. ${ }^{c}$ No yielding could be observed. ${ }^{d}$ All coefficients were obtained at $25^{\circ} \mathrm{C}$ : $\mathrm{P}$ is the permeability coefficient, $D$ is the diffusion coefficient, and $S$ is the solubility coefficient.

\section{Conclusions}

The main conclusions drawn from this work can be summarized as follows:

The rate of isothermal crystallization of $\mathrm{PET}^{\mathrm{t}} \mathrm{BI}$ copolymers both from the glassy state and from the melt decreases with the content of 5-tert-butyl isophthalic units. However, $\mathrm{PET}^{\mathrm{t}} \mathrm{BI}$ copolymers containing minor amounts of 5tert-butyl isophthalic units crystallize faster than PET. This striking result is 
probably due to the nucleating effect exerted by the bulky alkyl side groups. $\mathrm{PET}^{\mathrm{t}} \mathrm{BI}$ copolymers are able to crystallize both from the glassy and molten state up to contents of $20 \mathrm{~mol} \%$ and $15 \mathrm{~mol} \%$ of comonomeric units, respectively, but at much lower rates than PET. Crystalline PET ${ }^{\mathrm{t}} \mathrm{BI}$ copolymers retain exactly the same crystal structure as PET. The tensile modulus and strength of PET are not significantly affected by the presence of ${ }^{\mathrm{t}} \mathrm{BI}$ units, although the polymer becomes fairly brittle when the content in these units is over $15 \mathrm{~mol} \%$. The diffusion of gases in PET largely increases with the insertion of ${ }^{\mathrm{t}} \mathrm{BI}$ units, although the barrier properties of the polymer are not seriously affected.

\section{Acknowledgements}

This work has been supported by the Comisión Interministerial de Ciencia y Tecnología (CICYT) with Grant No. FD-97-1585 and project QUI990533. Financial support received from Catalana de Polímers, S.L. (Barcelona, Spain) is also gratefully acknowledged. The authors are indebted to Dr. A. Alla for his assistance with the DSC experiments.

\section{References}

1. Ha WS, Chun YK, Jang SS, Rhee DM, Park CR. J Polym Sci Part B: Polym Phys 1997; 35: 309.

2. a) Li B, Yu J, Lee S, Ree M. Eur Polym J 1999; 35: 1607. b) ibid Polymer 1999; 40: 5371.

3. Lee SW, Ree M, Park CE, Jung YK, Park CS, Jin YS, Bae DC. Polymer 1999; 40: 7137.

4. Wu TM. Chang CC, Yu TL. J Polym Sci Part B: Polym Phys 2000; 38: 2515.

5. Lodefier P, Daoust D, Jonas AM, Legras R. Macromol Symp 1999; 148: 59.

6. Karayannidis GP, Sideridou ID, Zamboulis DN, Bikiaris DN, Sakalis AJ. J Appl Polym Sci 2000; 78: 200. 
7. McCall MA, Caldwell JR, Moore HG, Beard HM. J Macromol Sci Chem 1969; A3: 911.

8. Watson WH, Grifton NC. U.S. Patent 3,365,425, 1968.

9. Fenoglio J, Foster JJ. J Polym Sci Polym Chem Ed 1990; 28: 2753.

10. Fenoglio J, Paschke EE, Stephens JR. U.S. Patent 4,895,928, 1990.

11. Schlatter MJ, Butler JC. U.S. Patent 2,794,794, 1957.

12. Keck MH. U.S. Patent 4,223,126, 1980.

13. Kint DPR, Martínez de llarduya A, Muñoz-Guerra S. J Polym Sci Part A: Polym Chem 2001; 39: 1994. 